Isaac I. Olufadewa1,2,3, Miracle A. Adesina1,2,4, Funmilayo R. Abudu ${ }^{1,5}$, Samuel D. Ayelawa ${ }^{1,5}$, Ruth I. Oladele ${ }^{1,2}$, Yusuf Babatunde ${ }^{1,6}$, Moyinoluwa J. Oladoye ${ }^{1,7}$, Oluwadara T. Akano ${ }^{1,5}$

${ }^{1}$ Slum and Rural Health Initiative Research Academy, Ibadan, Nigeria

${ }^{2}$ College of Medicine, University of Ibadan, Ibadan, Nigeria

${ }^{3}$ Pan African University of Life and Earth Sciences Institute

${ }^{4}$ Universal Care for Africa Foundation, St. Louis, United States

${ }^{5}$ College of Health Sciences, Obafemi Awolowo University, Ile-Ife, Nigeria

${ }^{6}$ Faculty of Pharmaceutical Sciences, University of Ilorin, Ilorin, Nigeria

${ }^{7}$ Faculty of Veterinary Medicine, University of Ibadan, Ibadan, Nigeria

\title{
The role of comprehensive sexuality education (CSE) in reimagining HIV/AIDS inequalities
}

\section{Corresponding author:}

Ruth Oladele, Slum and Rural Health Initiative Research Academy, Ibadan Nigeria, e-mail: roladele20@gmail.com

Medical Research Journal 2021; Volume 6, Number 1, 59-63 10.5603/MRJ.a2021.0006 Copyright (C) 2021 Via Medica ISSN 2451-2591 e-ISSN 2451-4101

\begin{abstract}
Over 70 million people globally have been infected with HIV since the beginning of the epidemic. HIV infection has neither a cure nor a vaccine; hence, education and awareness have been adopted to prevent the spread of the virus. Despite the action to reduce the HIV prevalence with access to effective information, prevention, diagnosis, treatment, and care, it remains a major health concern and a chronic health condition that could only be managed by enabling people living with the condition a better, longer, and healthy life. However, comprehensive sexuality education (CSE), which is a right-based approach that provides and equips people with the right knowledge on sexual education and reproductive health, can be utilised in sexual health promotion. It comprises seven essential components that focus on several aspects of sexuality. Thus, this paper provides evidence for the importance of CSE in reducing HIV prevalence, especially amongst the vulnerable population. The incorporation of long-term sexuality education programs in the school-based curriculum will contribute to the massive reduction in teenage pregnancies and abortion, and the decline in rates of sexually transmitted infections and HIV. It will also increase the knowledge about sexual and reproductive issues normalization and self-efficacy. Hence, CSE health educators and school teachers should be adequately trained in comprehensive sexuality education to curb the spread of HIV infection. Key words: comprehensive sexuality education; cSE; gender inequality; HIV inequality
\end{abstract}

Med Res J 2021; 6 (1): 59-63

\section{Introduction}

Comprehensive sexuality education (CSE) according to the Sexuality Information and Education Council of the United States (SIECUS), is defined as a life-long process of acquiring information and forming attitudes, beliefs, and values about identity, relationships, and intimacy [1]. It involves all kinds of right-based approach to pass and equip people with sexual education, including knowledge on reproductive health, Human Immunodeficiency Virus (HIV), family planning, disease prevention, embryology and anatomy, skills and attitude needed for the individual sexuality to be enjoyable [2, 3]. CSE centres on gender and human rights-based approach which could also be regarded as family life education, sex education, life skills education, or sometimes holistic sexuality education depending on the setting where the program is done [2]. CSE is not about getting information alone but allowing young people to explore and build the right attitudes toward their sexuality which will later be a great gain for them in the future [3, 4]. Different climes start their sexuality education at a different age. In some parts of Western Europe, the most common age is between $4-5$ years onward while most countries start at age 12-14 years onward [5].

Following the estimate of 38 million people living with HIV as of September 2018, it shows that 8 million people are not aware that they are HIV positive patients while 15 million persons are not being treated. This shows high inequality rates in the prevalence of HIV infection, 
access to testing and treatment services despite the efforts made in putting the HIV epidemic to an end [6]. HIV inequality varies depending on sex, age, religion, education status, and region. The inequalities should be handled according to their socioeconomic factors. The sub-Saharan African region is affected greatly being the country with the highest number of HIV infections (5.5\%) [6], hence a need for more attention. The importance of HIV testing cannot be overemphasized as this is the first step taken to knowing one's status and determining if further treatment and care are required or not. Lack of HIV screening will place the greater population at higher risk of new HIV infections [7]. Comprehensive sexuality education is crucial to resolving HIV inequalities hence putting an end to the HIV epidemic.

\section{History of comprehensive sexuality education}

Sexuality education has long existed for centuries right from the 1800s especially in the United States (US) and some western European countries [5, 8]. Sexuality education did not gain global recognition due to disagreement among many organizations, but as civilization, urbanization, and industrialization in the United States evolved, more attention was paid to it [9]. The US became the first country to initiate its first organizational body on sexuality education in 1905, called the American Society for Sanitary and Moral Prophylaxis, to reduce diseases associated with sexual contact [9]. After many decades, sexuality education grew tremendously and it gained public acceptance due to its importance and the information gotten from it; this instigated the move for this information to be addressed in homes, churches, and schools. As sexuality education continued to grow, it was then adopted by many other countries. It first began in Sweden in 1955 where it was added to school curriculum subject $[5,7]$, followed by many western European countries in the 1970s and 80s [5]. In Africa, CSE was taught in civics and hygiene classes and dated back as early as 1957 in Ghana [10]. The practice of sexuality education in schools continued to increase throughout the world. Today, sexuality education is an integral part of every educational system in the world.

\section{Components of comprehensive sexuality education}

There are seven essential components of comprehensive sexuality education namely; gender; sexual and reproductive health and HIV; sexual rights and sexual citizenship; pleasure; violence; diversity; relationship [10,11]. - Gender: perceptions of gender roles should be understandable, knowing the difference between sex and gender. Having full knowledge of gender bias in the community and the consequences as a result of self-stigmatization.

- Sexual and reproductive health and HIV: this includes the sexuality of each gender starting from puberty to menopause, and sexual problems. Myths should be cleared out on virginity, sexual response, social expectations, and also having respect for the individual body. Understanding HIV and other sexually transmitted infections, including transmission and symptoms should be duly explained.

- Sexual rights and sexual citizenship: a rights-based approach to sexual and reproductive health, understanding that sexuality and culture are diverse and dynamic. Knowledge of international human rights and national policies, law, and structures that relate to people's sexuality.

- Pleasure: understanding that sex should be enjoyable and consensual, understanding that sex is much more than just sexual intercourse but a healthy and normal part of everybody's life; the biology and emotions behind the human sexual response; gender and pleasure; sexual wellbeing; safer sex practices and pleasure; masturbation; love, lust, and relationship.

- Violence: Gender-based violence should be explored with various types of violence toward men and women in the society and how they manifest; sex without the consent of two partners and understanding it is unjustifiable and unacceptable; laws and right; support options available and seeking help; community norms (power, gender) and myths; prevention, including personal safety plans; self-defence techniques.

- Diversity: Recognizing and understanding the range of diversity in our lives (e.g., faith, culture, ethnicity, socioeconomic status, ability/disability, HIV status, and sexual orientation); a positive view of diversity; recognizing discrimination, its adverse effects, and how to deal with it.

- Relationships: Recognizing that relationships are constantly changing, there are different types of relationships (e.g., family, friends, sexual romantic, etc.); those changes include emotions, intimacy (emotional and physical); rights and responsibilities; power dynamics; recognizing healthy and unhealthy or coercive relationships; communication, trust, and honesty in relationships; peer pressure and social norms; that love and sex are not the same.

\section{The core principle of comprehensive sexuality education}

Sexuality education has reasons for its establishment and formation, and these are expected to be met. Comprehensive Sexuality Education: Advancing Human 
Rights, Gender Equality, and Improved Sexual and Reproductive Health highlighted the aims of sexuality education [5, 9, 11-13]. At the end of the information passed, the following must be met by CSE:

1. Intensity respect between individual and diversity;

2. Provide and strengthen young people in their participation to make decisions and critical thinking;

3. Encourage gender equality;

4. Communicate a positive, life-cycle approach to sexuality;

5. Entails information that has been scientifically proven;

6. Give a conducive and safe environment for ease of learning;

7. Including participatory teaching methods to help strengthen communication skills and decision-making abilities;

8. Address vulnerabilities, exclusion, and human rights violations, including gender-based violence and sexual abuse;

9. Gender and power issues should be addressed for better health outcomes in society.

\section{Benefits of comprehensive sexuality education}

Studies demonstrate that sexuality education provides many health benefits. Long-term sexuality education program reported in several European countries revealed a massive reduction in teenage pregnancies and abortion, decline in rates of sexually transmitted infections and HIV, increase self-confidence and invigorating skills to cope in different scenarios, empower young people to develop stronger and more meaningful relationships. Sexuality education has a positive impact on values and attitudes, and can even out the power dynamics in intimate relationships, contribution to the prevention of abuse and mutually respectful and consensual partnerships [10,13], increased knowledge, sexual and reproductive issues normalization, and self-efficacy $[14,15]$.

\section{Comprehensive sexuality education (CSE) and HIV}

Human Immunodeficiency Virus (HIV) is a global health crisis with over 70 million people [16] who have been infected within and between the spheres of countries and regions of the world [17]. This deadly virus is one of the most persistent epidemics among humanity that attacks the antibodies responsible for fighting against a bodily harmful pathogen, thus making infections and diseases more vulnerable [17, 18].
In an immunodeficient person, the virus destroys and impairs the function of the immune cells responsible for fighting against diseases and infections. HIV as of present has no cure or vaccine to prevent its occurrence; once it is contracted, it goes on for a lifetime [19]. If left untreated, HIV advances to its last stage, Acquired Immunodeficiency Syndrome (AIDS) [20]. Despite the action to reduce the HIV prevalence with access to effective information, prevention, diagnosis, treatment, and care, it remains a major health concern and a chronic health condition that could only be managed by enabling people living with the condition a better, longer, and healthy life.

The prevalence of HIV among women accounts for more than half of the number of people living with HIV in the world. In 2016, it was recorded globally that women living with HIV were between the ages of 15 and above with an estimation of 17.8 million [19]. Today, AIDS-related illnesses are one of the leading causes of death for women between 15-49 years of age [20]. The population of Africa with HIV incidence is about $10 \%$ [20]. HIV prevalence among adults in the sub-Saharan part of Africa has reduced by more than half; there were approximately 1 million fewer new HIV infections from 2000 to 2012 [20]. McCutchan reported that young women are acquiring HIV five to seven years earlier than their male counterparts [21]. Young men of the same age as women (10-24 years) are half less likely to contract the incurable virus $[22,23]$.

Comprehensive sexuality education is core to sound physical, mental, and social well-being of health. CSE is said to be of good quality when the sexuality of men, fundamental human rights, gender equality, adolescent relationships, and reproductive sexual health education are met. Young people derive benefits from CSE as it provides adequate information needed to protect themselves from sexual infections, unwanted pregnancy, and HIV, thereby promoting the central principle of CSE including tolerance, mutual respect, and non-domestic relationship violence, not just that alone, but has a positive impact on safer sexual behaviours, delaying sexual debut and increasing condom use [15].

The prevention of HIV was incorporated into sexuality education internationally in the 1980s [24]. Globally, the proportion of adolescents infected is larger than that of adults. Worldwide, multiple sex partners and unprotected sexual intercourses are the main routes of transmission of HIV among young individuals. HIV-related risk is common among young people due to their engagement in illicit sex, transactional sex, multiple sex partners, sexual violence, rape, and coercion [25]. However, school-based sex education has been reported to promote awareness of HIV infection among young people and to curb the spread of the infection, just as reaching out to a large number of people through the 
medium of a school-based intervention to equip and facilitate training, educational lessons, and group discussions for the young about their sexual activity and sexual life [26].

Gender inequality is an integral factor that affects increased HIV prevalence among young girls and women. UNESCO reported that this inequality among gender is linked to the decreased access of females to education or limited education and access to health information and services [27]. Many surveys have been conducted in different school environments on whether HIV prevention and sex education intervention among the youth is effective and whether it can be encouraged. A survey carried out on 758 students for 18 months showed that the introduction of reducing the risk curriculum (RTR) reduces the number of youth engaged in sexual intercourse during the 18 months, which reduced unprotected sex, either by increasing contraceptive use or delaying sexual intercourse. This survey shows that the knowledge of HIV-related risks and sexual behaviours is increasing, indicating that there is a chance of bridging the knowledge gap [26]. Kirby and Coyle concluded from their study that there is no significant association between abstinence and the delay of the sexual debut, while sexuality education was a potent means in bringing sexual risk to its minimum [28]. Speizer et al. reviewed a study on adolescent reproductive health intervention in developing countries. The study found that there is improved knowledge of HIV, its transmission, prevention, and management [28]. Findings made in examining comprehensive sexuality education status in over 48 countries globally revealed that $80 \%$ of the countries are working with strategies and policies that support comprehensive sexuality education; some countries, such as Latin America and the Caribbean, have signed a declaration to affirm HIV and school-based sexuality education. This study has further revealed that comprehensive sex education programs significantly reduce HIV, STI, and unintended pregnancies [25, 30].

\section{Reshaping HIV inequality using comprehensive sexuality education}

Joanne Herat, a senior program specialist in Health Education at UNESCO, reported that many regional and global policies still revealed significant gaps despite the effort of policymakers and political will [25]. Many organizations, including UNESCO, UNAIDS, UNFPA, $\mathrm{WHO}$, and UN Women, came together to publish the International Technical Guidance on Sexuality Education in 2018. The sole aim of this guidance is to help decision- and policymakers create a precise and accurate curriculum for children and adolescents in their countries [26]. Furthermore, in 48 countries across the world, the CSE status was examined in a global review published by UNESCO, collaborated with UNAIDS Secretariat and United Nations Population Fund (UNFPA) in 2015 titled "Emerging Evidence Lesson and Practice in Comprehensive Sexuality Education". The report revealed that $80 \%$ of assessed countries have policies or strategies in place that support CSE [27]. Governments and stakeholders have targeted sexual health school-based education as a key strategy in reducing these issues to the lowest limit. Research also found that the teachers must be trained as it is for the effective delivery of CSE.

More so, many studies had proved that comprehensive sexuality education gives correct developmental, complete, accurate, and appropriate human sexuality information including risk-reduction strategies. In 2012, a study was conducted to access 66 sexual risk-reduction programs; the result of the study revealed that these programs are effective global health methods to bring about a reduction in adolescent HIV, STIs, and pregnancy [29]. Also, the national survey of Family Growth examined the effect and impact of sex education on youth between age 15-20, and it was found that teens who received the comprehensive sexuality education were about $50 \%$ less likely to experience pregnancy than those who were taught to abstain from sex until being married [31].

A study carried out by Euphemia et al. showed that the greater number of those tested in the past 12 months came from the poor and least educated, compared to the rich and educated. Knowledge of sexuality will encourage individuals to debunk myths, go for screening and be properly counselled [32].

\section{Recommendations}

1. Vulnerable adolescents such as the poor living in a rural communities, the uneducated, and sex workers cater to their needs, should be paid close attention [33] and properly counselled on how to survive without the abuse of one gender or the other;

2. Parents should try as much as possible to educate their children on a different part of their body and disease-associated to them, especially the genitals;

3. Schools should incorporate comprehensive sexuality education [34] in their curriculum;

4. The advocate must try as much as possible to break barriers to sexual health information and services including lack of health care facilities and poverty.

\section{Conclusion}

The population of people living with HIV keeps increasing daily; the prevalence of HIV infection is highest 
in sub-Saharan African countries at $5.5 \%$. This is a result of the inequalities in HIV prevention, testing, and management services. HIV inequality can be resolved by improving sexuality education. This can enlighten individuals on the basics of sexuality, their rights to their sexual health, the prevention of HIV and other STDs, and also reduce the stigmatization. Including CSE in both secondary and tertiary student's curriculum will greatly help in reducing HIV inequality.

\section{Funding: The study was self-funded.}

\section{Conflict of interest: Authors declare no conflicting interest.}

\section{References}

1. SIECUS State Profiles: Guidelines for Comprehensive Sexuality Education. Washington, DC: National guidelines task force, 3rd edition; SIECUS. ; 2004.

2. Keogh S, Stillman M, Leong E, et al. Measuring the quality of sexuality education implementation at the school level in low- and middle-income countries. Sex Education. 2019; 20(2): 119-137, doi: 10.1080/14681811.2019.1625762.

3. United Nations Population Fund. Comprehensive Sexuality Education http://www.unfpa.org/comprehensive-sexuality-education (2020, November 30).

4. United Nations Educational, Scientific and Cultural Organisation. Why comprehensive sexuality education is important. https://en.unesco. org/news/why-comprehensive-sexuality-education-important (2020, November 30)

5. Bonjour M, van de. Comprehensive Sexuality Education: Knowledge File. Utrecht: Rutgers. ; 2018: 31p

6. Challacombe SJ, Challacombe SJ. Global oral inequalities in HIV infection. Oral Dis. 2016; 22 Suppl 1: 35-41, doi: 10.1111/odi.12408, indexed in Pubmed: 27109270.

7. Cremin I, Cauchemez S, Garnett GP, et al. Patterns of uptake of HIV testing in sub-Saharan Africa in the pre-treatment era. Trop Med Int Health. 2012; 17(8): e26-e37, doi: 10.1111/j.1365-3156.2011.02937.x, indexed in Pubmed: 22943376.

8. European Expert Group on Sexuality Education. Sexuality education - what is it? Sex Education. 2015; 16(4): 427-431, doi: 10.1080/14681811.2015.1100599.

9. Herrman J, Solano P, Stotz L, et al. Comprehensive Sexuality Education: A Historical and Comparative Analysis of Public Opinion American Journal of Sexuality Education. 2013; 8(3): 140-159, doi 10.1080/15546128.2013.828342

10. International Planned Parenthood Federation. Promoting comprehensive sexuality education in Ghana. https://www.ippfar org/blogs/promoting-comprehensive-sexuality-education-ghana (2020, November 30)

11. United Nations Population Fund. Operational guidance for comprehensive sexuality education: a focus on human rights and gender. New York: UNFPA ; 2014: 76p.

12. United Nations Population Fund. Comprehensive sexuality education advancing human rights, gender equality and improved sexual and reproductive health. Bogota: UNFPA. ; 2010: 74p.

13. United Nations Educational, Scientific and Cultural Organisation. HIV and Sexuality Education. http://en.unesco.org/themes/health-education/hiv-sexuality-education (2020, December 1).

14. Rahmani A, Merghati-Khoei E, Fallahi A. Perceived Advantages and Disadvantages of Sex Education in Young Women: A Qualitative Study. International Journal of High Risk Behaviors and Addiction. 2018; 7(2), doi: 10.5812/ijhrba.57221.
15. Fonner VA, Armstrong KS, Kennedy CE, et al. School based sex education and HIV prevention in low- and middle-income countries: a systematic review and meta-analysis. PLoS One. 2014; 9(3): e89692, doi: 10.1371/journal.pone.0089692, indexed in Pubmed: 24594648.

16. Fajardo-Ortiz D, Lopez-Cervantes $M$, Duran L, et al. The emergence and evolution of the research fronts in HIV/AIDS research. PLoS One. 2017; 12(5): e0178293, doi: 10.1371/journal.pone.0178293, indexed in Pubmed: 28542584

17. Centers for Disease Control and Prevention. About HIV. https://www cdc.gov/hiv/basics/whatishiv.html (2020, December 3)

18. HIV.gov. What are HIV and AIDS? https://www.hiv.gov/hiv-basics/overview/about-hiv-and-aids/what-are-hiv-and-aids (2020, December 3).

19. UN WOMEN. Facts, and figures: HIV and AIDS. c2016. https://Www. unwomen.org/en/what-we-do/hiv-and-aids/facts-and-figures (2020 November 30)

20. UNAIDS. Women and HIV — A spotlight on adolescent girls and young women. https://www.unaids.org/en/resources/documents/2019/women-and-hiv (2020, November, 30).

21. McCutchan FE. Global epidemiology of HIV. J Med Virology. 2006; 78(S1): S7-12.

22. Dellar RC, Dlamini S, Karim QA Adolescent girls and young women: key populations for HIV epidemic control. J Int AIDS Soc. 2015; 18(2 Suppl 1): 19408, doi: 10.7448/IAS.18.2.19408, indexed in Pubmed: 25724504

23. Avert. Women and girls, HIV and AIDS[Internet]. c2019. https://www avert.org/professionals/hiv-social-issues/key-affected-populations/women (2020, November 30)

24. Herrman J, Solano P, Stotz L, et al. Comprehensive Sexuality Education: A Historical and Comparative Analysis of Public Opinion American Journal of Sexuality Education. 2013; 8(3): 140-159, doi: 10.1080/15546128.2013.828342.

25. Gallant M, Maticka-Tyndale E. School-based HIV prevention programmes for African youth. Soc Sci Med. 2004; 58(7): 1337-1351, doi: 10.1016/S0277-9536(03)00331-9, indexed in Pubmed: 14759680.

26. Kirby D, Coyle K. School-based Programs to Reduce Sexual Risk-taking Behavior. Children and Youth Services Review. 1997; 19(5-6) 415-436, doi: 10.1016/s0190-7409(97)00025-X.

27. Fonner VA, Armstrong KS, Kennedy CE, et al. School based sex education and HIV prevention in low- and middle-income countries a systematic review and meta-analysis. PLoS One. 2014; 9(3): e89692, doi: 10.1371/journal.pone.0089692, indexed in Pubmed: 24594648

28. Speizer IS, Magnani RJ, Colvin CE. The effectiveness of adolescent reproductive health interventions in developing countries: a review of the evidence. J Adolesc Health. 2003; 33(5): 324-348, doi: 10.1016/s1054-139x(02)00535-9, indexed in Pubmed: 14596955

29. Sipe TA Chin HB, Elder R et al. Community Preventive Services Task Force, Community Preventive Services Task Force. The effectiveness of group-based comprehensive risk-reduction and abstinence education interventions to prevent or reduce the risk of adolescent pregnancy, human immunodeficiency virus, and sexually transmitted infections: two systematic reviews for the Guide to Community Preventive Services. Am J Prev Med. 2012; 42(3): 272-294, doi: 10.1016/j.amepre.2011.11.006, indexed in Pubmed: 22341164.

30. United Nations Educational, Scientific and Cultural Organisation. Global Review finds Comprehensive Sexuality Education key to gender equality and reproductive health. https://www. un.org/youthenvoy/2016/03/comprehensive-sexuality-education/ (2020, November 30)

31. Kohler PK Manhart LE, Lafferty WE. Abstinence-only and comprehensive sex education and the initiation of sexual activity and teen pregnancy. J Adolesc Health. 2008; 42(4): 344-351, doi: 10.1016/j. jadohealth.2007.08.026, indexed in Pubmed: 18346659.

32. Sibanda EL, Taegtmeyer M. Inequalities in uptake of HIV testing despite scale-up. Lancet Glob Health. 2020; 8(6): e744-e745, doi: 10.1016/S2214-109X(20)30208-4, indexed in Pubmed: 32446337.

33. Olufadewa II, Adesina MA, Ayorinde TA. From Africa to the world Re-imagining Africa's research capacity and culture in the global knowledge econony. Journal of Global Health. 2020; 10(1), doi: 10.7189/jogh.10.010321.

34. Adesina MA, Olufadewa II. Comprehensive Sexuality Education (CSE) curriculum in 10 East and Southern Africa Countries and HIV prevalence among the youth. European Journal of Environmental and Public Health. 2020, 4(1): em0035 https:doi.org/10.29333/ejeph/6009. 